Norms, values and corruption. A case study of an EU procurement process in an African country

Peter Stiernstedt and Mark Button

\title{
Introduction
}

Imagine an anti-corruption EU policy maker standing in one of the many offices in Brussels. Hands filled with binders and papers, ready to argue for a new anti-corruption policy as part of the EU Global Strategy for improved African relations. Suddenly, a single pen slips from his grip and gravity unequivocally pulls it to the floor. The policy maker looks down at the pen and hopes to create an anti-corruption policy as universally and unequivocally compelling as gravity.

This chapter will explore the role of morality in corruption. Going down a fairly well-travelled route of examining corruption in the procurement process, the analysis uses a somewhat less commonly applied axiological lens. The paper will then establish the aspiring diction of the EU in terms of corruption as an expression of a moral high ground on how to, at least intellectually, deal with the phenomenon. Having a clear position on the immorality of corruption is obviously laudable, but problems arise when rhetoric is translated to reality. This is illustrated by delineating the EU moral stance on corruption and looking at how this relates to a case study of corruption in the procurement process.

\section{Corruption, norms and values}

Corruption affects most, if not all things in society and its detrimental effects are now acknowledged at all levels, reflected all the way from the opinion of the single citizen as well as high-up into supra-national policy (Sampford, Shacklock, Connors, and Galtung 2006). There is, however, a major disconnect somewhere in between, where global anti-corruption initiatives seem 
very capable of formulating and implementing anti-corruption policies, but incapable of generating effective solutions. At least not without running the risk of those policies being watered-down to a point far beyond them being able to translate the ambitious rhetoric to reality (Persson, Rothstein, and Teorell 2013).

It is sometimes argued that one of the reasons for the inefficacy is the rather large variation in values and norms across the world - the principles that guide an individual on how to distinguish right from wrong. It is not hard to imagine different social axioms in, for example, Europe and Africa that affect intentions, decisions and, ultimately, actions. While this discussion is confined to an inter-continental setting, the argument may be equally true for intra-social contexts within and between the sometimes rather different nation sates of each continent (Heidenheimer 2002). Hence, a generalization of either European or African morality will be just that - a general picture of a particular motif. That, however, does not necessarily make the comparison less relevant as many European organizations and governments operate in African countries seeking to transplant their 'good practices' there. It may also be useful to benchmark what many might perceive as lower moral standards of anti-corruption in African countries, against perceived higher standards in European nations. On the other hand, there may not be a need for variation in morals - perhaps there is a universal moral high ground that could and should be adopted globally.

The EU has a well-established and clear position when it comes to corruption as an immoral and illegal action. At least rhetorically. This does not necessarily translate "as opposed to practically" but rather "as in contrast to reality" where this more often than not deviates from the intrinsic behavior of those subscribing to the moral statements. Taking something of a moral high ground the EU stated in a 2003 communication from the Commission its position on corruption:

Corrupt acts have to be detected and prosecuted and offenders have to be punished and deprived of their illicit proceeds. 
At the same time, opportunities for corrupt practices have to be reduced and potential conflicts of interest have to be prevented through transparent and accountable administrative structures at legislative, executive and judicial level as well as in the private sector (Wensink and Vet 2013).

The contrast to this commendable statement appears when examining the actual outcomes and real events, which point to something a bit murkier. Particularly when operating in areas where culture differs and the underpinning norms and values arguably differ significantly. This opens the door for a deep axiological analysis into an issue for which some claim that there are no right or wrong answers. It is here, however, where our position departs from that which is most commonly adopted in social science settings. We claim that there are answers, sometimes rather clear-cut, to questions about right and wrong. That there is a relationship between axiological science and human morality.

The value of values is self-evident and axiology is the science of those values. The concept of axiology - that some "things"1 are more valuable than others, has been instrumental to human evolution throughout time. As outlined by Bahm (1993), axiology is not only important as a science but also vital to understanding global problems, such as corruption, observing its usefulness relative to causes, understanding, and overcoming such phenomena. Generally, science provides indicators on how to get what we as humans and societies dictate as valuable but seldom, or never, what ought to be valued. Science is often viewed as dealing with facts and for some reason values seem to belong to a different sphere. It is this separation with which we take issue. We believe it to be, as a phenomenon occasionally complex, as an intellectual fallacy persuasive, but nevertheless, ultimately false. In line with an argument prominently promoted by Harris (2011) the claim is for values to also be facts, although certain kinds of facts - facts that speak about the well-being of conscious human beings. The conditions for that well-being represent a continuum of value-based

\footnotetext{
${ }^{1}$ The concept of "things" is not restricted to physical things but meant to encompass basically everything, including but not limited to, feelings, desires, ideas, etc. - all considered "things" that have intrinsic value.
} 
factual claims and there are right and wrong answers to decisions when moving along this continuum. In short, irrespective of if it is fully understood, there are truths to be known about how human societies flourish.

This can obviously be analyzed at different levels, but if concerned with corruption, it by necessity involves the human decision-making process. This is a result of corruption being defined as the endresult of a cognitive process formulated as:

"Corruption is an improbity or decay in the decision-making process in which a decision-maker (in a private corporation or in a public service) consents or demands to deviate from the criterion, which should rule his decision making, in exchange for a reward, the promise or expectation of it." (Duyne 2001)

Fundamental to that decision-making process is a degree of understanding of the decisions taken. There are, however, sometimes limits to the extent to which the decisions are actually understood and many of the actions that begin cycles of corruption are products of the intuitive judgment system, which means that they are rapidly arrived at, less than consciously considered, and thus unintentional in their ethical dubiousness (Darley 2005). The intuitive judgment system is in turn conditioned by its operational context, the norms and values expressed by the culture of the decision-maker.

Because human experience of the world and ourselves within it is realized in the brain - this is where decisions, conscious or otherwise, are born. Thus, changes in culture are, in essence, changes in cerebral operating parameters. The resulting function within these parameters, is revealed by behavior and subsequent societal structures - either moral or immoral, impartial or corrupt. In a typology developed by Rusch (2016) in his work on the psychology of corruption there are at least six types of faulty intuition that influence corrupt behavior. The first type is the overconfidence effect where a person's subjective confidence in judgment is greater than the objective accuracy of those judgments (Pallier et al. 2002). This can create a gap between how people believe they would 
behave and how they actually behave (Nohria 2015). Bribery prosecutions highlight some key factors, such as: intense business negotiations for high-value contracts, licenses, or concessions (Rusch 2016) - all inherent parts of the procurement process. The second type is reciprocation, where people try to repay, in-kind, what another person has provided (Cialdini 1993). This cannot only increase susceptibility to corruption but also aid in sustaining a corrupt relationship. The third type is scarcity, where the perceived opportunity to freely choose something of value is threatened through some type of scarcity, e.g. limited time or resource availability. Research shows that when under extreme time pressure, unethical behavior is more likely (Nohria 2015), and possibly exacerbated by "loss aversion" - an unconscious bias that makes people weight losses more heavily than gains (Kahneman 2011). The fourth type is commitment and consistency with past behavior, i.e. once a decision is made it creates an internal pressure to behave consistently with that commitment (Cialdini 1993). This can sustain long-term commitments to corrupt behavior through "ethical fading" - the ability to behave unethically or overlook the unethical behavior of others "while maintaining a positive self-image" (Bazerman and Tenbrunsel 2011). In short, if a positive image of oneself as ethical is maintained, one may infer that one's actions are consistent with that self-image. The fifth type is social proof, which is the tendency, in ambiguous or confusing situations, to take cues from others in the vicinity on how to act (Cialdini 1993). This, coupled with "pluralistic ignorance"2 can lead to an unintended diffusion of responsibility where no action is taken against blatantly corrupt behavior. The sixth and final type is confirmation bias, prompting an individual to look for confirming evidence of a decision before seeking disconfirming evidence (Kahneman 2011). This is important when observing ongoing corruption where confirmation bias is likely to affect the ability to process and act on that initial observation. It does so by influencing the

\footnotetext{
${ }^{2}$ Pluralistic ignorance means that an individual rather than realising that the other silent individuals are being silent for exactly the same reasons, the individual tends to conclude that these others think that the act is an acceptably moral one and are keeping silent for that reason. See Darley (2005).
} 
observer to seek out and accept less malign explanations for the observed corrupt behavior, which is also consistent with ethical fading, enabling the reinforcement of an ethical self-image.

This goes to show that corrupt behavior is largely conditioned by the understanding of the actions as being immoral, i.e. in conflict with some set of universal values and norms. It is obviously not easy to establish what those universal values and norms are, but nonetheless not impossible. And, in a way, that is exactly what is expressed in the heavy wording of the EU. Consequently, not understanding the immorality of corrupt behavior does not mean that there is no truth to the fact that there is an axiological high ground to be found. With values reduced to facts about the conscious experience, the axiological terrain can be visualized - what Harris (2011) refers to as a moral landscape. With peaks and valleys, where increased spatial elevation corresponds to a societal state of moral, non-corrupt, behavior on both an individual and collective level. Decisions and subsequent actions determine the movement over the moral landscape, with distinct right and wrong answers to how to behave in order to reach any of the peaks. It is this view that changes morality from something largely intangible to something quantifiable - with room for debate on the expectations of optimal behavior.

Having said that, this does not imply that there is only one optimal state of individual and collective behavior leading to a well-governed, non-corrupt society. Early work on the science of values has expressed doubts about traditional doctrines (Bahm 1993) and the proliferation of new conjectures to this day characterize the complexity of moral landscape topography. Therefore, it is evident that there are more than one peak and thus different coordinates that align the notion of individual selfinterest utility maximization and the collective good. Consider the following analogy adapted from Harris (2010) on food and nutrition. There is not one singular right food to eat but rather a range of items that constitute healthy food. Nonetheless, there is a clear distinction between the extremes of food and poison. The fact that there are many right answers to the question, "What is food?" should 
not tempt the conclusion that there are no truths to be known about nutrition. As with this analogy, the distinction that corruption is poison to society (at least a well-governed one) may be equally obvious.

Having established the important philosophical underpinnings for this research an analytical discussion can be made around the axiologically charged morality of corruption. By identifying the expressed moral high ground taken by the EU and acknowledging this as one of the peaks of the moral landscape, rhetoric can be compared and related to reality. To do so requires a theoretical context in which corruption may permeate coupled with empirical data to identify and illustrate moral shortcomings and corrupt behavior.

Thus, the first objective is to identify such a context and secondly, to obtain some in-depth empirical data within that context. Among data rich areas, public procurement stands out. As expressed by the OECD in its Principles for Integrity in Public Procurement:

"weak governance in public procurement hinders market competition and raises the price paid by the administration for goods and services, direct impacting public expenditures and therefore taxpayers' resources. The financial interests at stake, and the close interaction between the public and private sectors, make public procurement a major risk area. [...]" (OECD 2009)

Public procurement accounts for roughly one third of government spending, has a high level of perceived corruption, and subsequently also an innovative research environment turning out many new corruption proxies (OECD 2007, 2013). The procurement process has also been identified by the EU as particularly susceptible to being influenced by acts of corruption (COM(2014) 38). Within this context the corrupt requirements are thought to be a) corrupt transactions allowing for rent generation, b) particularistic relations underpinning collective action of corrupt groups; c) 
organizations enabling rent allocation (public organizations); and d) organizations extracting corrupt rents (private companies) (Fazekas, Cingolani, and Tóth 2016). With unique access to documents, recordings and key stakeholders in a case of alleged corruption involving all the areas,

a) through d), the following section will set out the methodological approach applied in this paper.

\section{Methodology}

The methodology is broadly informed by Williamson's (2006) work on undertaking research using a constructivist philosophical framework and ethnographic techniques. From an epistemological perspective the approach is considered "soft," being highly qualitative and interpretive in its nature. The method was designed in line with Feldman's (2003) standard view, to reflect a set of conclusions that accurately captures reflective common sense. Ethnography, commonly used to study social interactions, behavior and perceptions that take place between individuals, within small groups and large communities, is well-suited for this purpose. This is because the aim is to provide insights into people's perceptions, interpretations and actions through the collection and examination of recorded data, detailed observations as well as interviews. As Hammersley (1990) states, "The task [of ethnographers] is to document the culture, the perspectives and practices, of the people in these settings. The aim is to 'get inside' the way each group of people sees the world."

The main advantage of an ethnographic approach in this application is that it allows the researchers to "immerse" themselves in the very context of the situation. There is clear value in doing so where there may be misleading presumptions about a culture (Robson 2011), where morality obviously plays a significant part. Thereby, it is possible to generate a deep understanding of the decisions and actions of the participants within a specific social context. The close proximity to participants also provides the opportunity to gain insights to social practices that generally are hidden from public view - that is deviant, often immoral and corrupt behavior. 
Further, three key features of an ethnographic approach generally are; first, a strong emphasis on exploring the nature of the social phenomenon of corruption (rather than setting out a hypothesis to test); second, the suitability when primarily working with "unstructured" data, i.e. data that is not specifically coded at the time of collection and does not belong to a set analytical category; and third, the preferable narrow nature of an investigation few, in this case only one, case. All of this contributes to the applicability of this approach to this particular research setting, studying human behavior from a vantage point fundamentally based on verbal accounts.

There are two types of verbal accounts used in this research, on the one hand there are recordings of conversations and meetings, and on the other, new and complementary data has been collected through interviews. The interviews have been informal in nature and can be described more as participant narratives than structured question-answer type interviews. This allows for natural and uncoerced discussion of relevant issues and the possibility to ask intuitive questions. It is partly this "casual" nature of this interviewing style that allows for eliciting candid accounts from the participants.

Moreover, the research used documentary data, including but limited to: meeting minutes, newspaper articles, participant notes, official documents, etc. The empirical data is inductively analyzed around four predetermined categories, described below, drawing upon the emerging themes to generate a tentative theoretical explanation around the role of universal morals in anticorruption policy. The idea is not to argue for a single case to be representative of anything more than it is, but to exemplify that which is discussed in a highly tangible and understandable manner.

\section{'Project Fortress'}

The case involves a significant - circa $€ 100$ million - EU-funded project to build a major piece of infrastructure in a war-torn country in Africa. The case is still part of an ongoing legal process and 
for this reason the real names of the actors and the project will not be used and instead it shall be called 'Project Fortress'. The case begins with the desire for the EU to fund the development of Project Fortress in the African country. As illustrated by the EU Global Strategy setting out the EU's core interests and principles for engaging in the wider world, in areas such as security, defense and resilience building. As with any major project, there are extensive rules and regulations on how contracts are awarded, in general. In line with these, a tender for the contract was issued. This tender set out in detail, the requirements of the project covering issues such as technical specifications, eligibility of tenderers, evaluation procedures, and content of the tender.

Such large projects are common and there are experienced companies usually eager to create consortiums of companies to bid for such projects, thus building coalitions, which bring the relevant strengths and expertise to the consortium to maximize the chances of success. For Project Fortress the tender set out the following services to be provided, which encompassed both construction and service provision:

- Accommodations and offices space;

- Management support services;

- A comprehensive security service including inter alia static guards, foot patrols, access control, vigilance and close protection services, risk analysis, the provision of secure movements within the secure zone and beyond;

- Medical support;

- Communication and Information Systems services;

- Standard IT infrastructure and services.

The tender document sets out a detailed scoring system for assessing the bid to enable the decisionmakers to evaluate the technical and financial aspects of the bid. As with any points system in the 
award of such contracts there are always some criteria, which are open to subjective judgment. The ultimate financial cost of the bid is an objective criterion - if the bids are seeking to deliver the same project. Thus, if consortium $\mathrm{X}$ is $€ 5$ million cheaper than consortium $\mathrm{Y}$, this cost difference cannot be subject to subjective judgement. Many criteria will, however, always be much more open to interpretation and the extent to which the 0 to 10 points are allocated. In this particular tender for example there were up to 10 points on offer for each of the following (not all are listed):

- Degree of understanding of the project, risk analysis, identification of operational challenges and capabilities/measures to respond to these challenges;

- Clarity, readability and personalization; and

- Command and Control, capabilities, interoperability with other actors present on-site, etc.

These are all open to interpretation and the total points available can, for this type of case, be several hundreds. It is important to emphasize this discretion because it provides an opportunity for the decision-makers involved to mark up a preferred supplier and down a non-preferred supplier. Such actions might not be driven by corruption, rather contractor preferences or dislikes, but they also provide the opportunity for corrupt acts i.e. decision-makers takes bribe and uses that to favor bribe-payer or thwart a non-payer. Therefore, there is an opportunity for those who assess the bids to influence the outcome, as the score is based upon the price and technical assessment, which they have a role in determining. The points are published in the tender document and the decisionmakers are normally known. If bidders can also secure closer access to the decision-maker, to gain inside information on how the points will be assessed, they can also secure an advantage over competitors that lack that proximity. Such advantages can provide a much more hidden route to corruption, because the end point when bids are submitted, the bid with inside information is likely to look much better than the others. Thus, the final 'objective' assessment is not corrupt at all; the corruption occurred long before the bid reached this stage. 
It is also important in some cases to consider those in positions of power and influence over those who actually do the evaluation or work in partnership with them, as corruption can also be found at arm's length. For example, consider a superior suggesting to a decision-maker that company X should get a contract If the decision-maker does not comply there is an insinuation that such behavior would not be career beneficial (stick) where, compliance would be (carrot).

In this particular case, there were at least three consortiums bidding for the work. The winning consortium, which for the purposes of this paper we shall call 'African Partnership', consisted of six companies during the bidding process, four of which were sub-contractors and the two main tendering companies were both well-known international companies. It is the winning of 'Project Fortress' by the 'African Partnership' where the case of alleged corruption arises.

The consortium was led by a French national who we shall call 'Mr. Monde,' who is Deputy Chief Executive of a construction company we shall call 'Hopscotch.' All of the main companies and actors are listed in Table 1 below. The successful bidders were all large global companies from beyond the African country where the project was to take place. During the bidding, however, the consortium involved a local company, which we shall call 'Local security solutions' which is headed by a charismatic leader with antecedents, strong connections and experience of working in the country, who we shall call 'Mr. Alan'. Local security solutions had a strong track record for supplying security in this, a particularly difficult country prone to corruption. Further, the company possessed the necessary authorizations from the government to pursue the project - something that was likely to be difficult, and if nothing else time-consuming, to secure. As with any large-scale project of this size, there were regular meetings and exchanges of information between the partners in the consortium and the officials overseeing the tender - as there are always an extensive list of queries to be resolved.

The consortium was looking in a very strong position to win the bid and in November of the year of the award of the contract, the consortium met to discuss the bid they were likely to win. The 
meeting was divided into two parts. The first involved all the parties, and other than the usual consortium discussions, there was nothing unusual. However, at the end of the meeting Mr. Alan (minus his two employees) was asked to stay for an additional meeting with the consortium members (bar representatives from Alarmsafe and Makes). Mr. Alan thought this was very unusual, so used his mobile phone to record the meeting. In this meeting, Mr. Clong states:

There are some people I'm going to thank, and remember that these people still have the power to cancel the deal (...) He told me, "I want guarantees" (...) It is him who made the figures, he is going to expect some compensation.

Mr. Clong assures that this committee is useful:

It would be a shame to deprive us of the support of these people. I say "these people" because there, they open all kind of possibilities for us.

The discussions continue and it becomes clear to Mr. Alan that knowledge of these compensations is well-known when Mr. Pudsey from Oasis interjects to correct others that the percentage is 3\% not 2\%. Not all are happy and 'Mr. Rambo' from 'Secureland' is concerned that it is not possible to 'pay' EU officials. However, after some debate the meeting resolves to create a new line of expenditure to cover the costs of the $3 \%$. Mr. Alan decides to play along at this point, not sure of how to proceed. It is clear, however, that the representatives of Hopscotch, Oasis and Secureland are prepared to pay a 'fee' or bribe of $3 \%$ of the contract to EU officials for the award of it.

The meeting ends and Mr. Alan reflects long and hard on the discussion. In little over a month, the contract is signed, but a few weeks after this Mr. Alan withdraws from the consortium. Other consortium members claim Mr. Alan was seeking to blackmail the consortium to secure a higher stake in revenues, but Mr. Alan - who is committed to his country of origin and the development of a less corrupt society - claims to be very unhappy to be involved in a corrupt contract and willing to pay the price of non-involvement. 
Table 1. Principal companies and actors in the corruption case - 'Project Fortress'

\begin{tabular}{|c|c|}
\hline Actor/Entity & Description \\
\hline \multicolumn{2}{|l|}{ Tendering companies } \\
\hline African Partnership & Successful Consortium \\
\hline \multicolumn{2}{|l|}{ Tendering companies } \\
\hline Hopscotch & construction \\
\hline Oasis Services & facilities management \\
\hline \multicolumn{2}{|l|}{ Sub-contractors } \\
\hline Secureland & security services \\
\hline Alarmsafe & security equipment and systems \\
\hline Makes & general services \\
\hline \multicolumn{2}{|l|}{ The victim company } \\
\hline Local security solutions & security and local consultancy \\
\hline \multicolumn{2}{|l|}{ The other company } \\
\hline \multicolumn{2}{|l|}{ EU Lobbying Consultants } \\
\hline Principal Actors & \\
\hline
\end{tabular}




\begin{tabular}{|l|l|}
\hline Actor/Entity & Description \\
\hline Mr. Monde & Consortium leader and Deputy CEO of \\
\hline Mr. Alan & CEO of Local Security Solutions \\
\hline Mr. Noir & Lead EU Decision-maker \\
\hline Mr. Pudsey & Oasis Lead \\
\hline Mr. Clong & Paid lobbyist for consortium \\
\hline Mr. Rambo & Lead from Secureland \\
\hline & \\
\hline
\end{tabular}

Mr. Alan begins to then seek to expose what has happened. Before that phase of the case is described, however, it is worth stepping back in time to when Mr. Alan first became involved. A couple of years before the award of the contract Mr. Alan had been invited by Mr. Clong, at the time a Military official attached to the EU, for dinner with Mr. Noir an EU official, also a former military officer from the same country who seems to know Mr. Clong. Further observations suggest they do know each other very well. Both Mr. Clong and Mr. Noir express interest in the African country and little over a year later Mr. Noir is presiding over 'Project Fortress' with responsibility to implement it. Over the 18 months from publication of the tender to its award there are strong suspicions that Mr. Clong has inside information, which is helping the consortium develop a much stronger bid.

The evidence suggests that it was Mr. Noir who was expecting the 'commission' and who had been helping Mr. Clong. The scrutiny of the project also led to further interesting discoveries when it 
transpired that Mr. Noir was founder of a company listed in the UK called 'EU Lobbying Consultants.' It would seem highly unusual for a senior EU official to own such a company. As the bidding for the contract was ongoing, hidden beneath the surface was a decision-maker and a bidder with a relationship (how close of a relationship is difficult to determine) and a decision-maker with a company in a different country, which is unusual for such decision-makers. Although this alone was not yet clear evidence of corruption, it surely was evidence of a conflict of interest that should have been declared so that alternative decision-makers could be identified.

Returning to the fallout from Mr. Alan's decision to withdraw, his first act was to contact the superiors of the consortium partners. They, however, were very defensive and sought to turn on Mr. Alan as being the corruptor himself, seeking to blackmail the consortium to secure a better stake. Indeed, when Mr. Clong was presented with evidence of the recording of the meeting he changed his line from denying any corruption to describing it as a "trick" to both ensure the loyalty of the local partner and make him lower his expectations. He said:

"I had indeed tried to convince Mr. Alan that I had a contact within the EU, assuring me of getting the market so that he would have made a mistake if he had joined a competing team or had failed our bid by an untimely withdrawal, but also that the commission of this contact would make physically impossible the payment of the extravagant amount that he [Mr. Alan] requested."

The consortium members all held the line that there was no corruption and that Mr. Alan was in fact the problem and the corruptor. Several months after his withdrawal from the consortium, Mr. Alan reported the case to Olaf and the French police. The EU denies there are any discrepancies in the bidding process and the investigations continue. Cases such as this are notoriously difficult to investigate and it is nearly impossible to prove corruption. They invariably rely on a whistleblower coming forward with direct evidence of the corruption. Without that, unless there is a paper-trail or covert surveillance evidence, suspicions of corruption are very difficult to prove. Large and 
sophisticated cases such as this often involve actors that are skilled at covering their tracks. Mr. Alan was not at the center of the consortium or the corruption and therefore, other than his recorded meeting, he possessed no other evidence.

The other actors were able to offer a plausible alternative to explain their discussions. The EU - like many other organizations in a similar position - was faced with a difficult situation. As a proponent of anti-corruption measures, it would be very concerned to discover potential corruption involving a senior decision-maker at the heart of the organization. Its default position - until proven otherwise was bound to deny any corruption, afterall, if it does transpire to be the case it will be very embarrassing to it. It remains to be seen whether any corruption will be provable in a court of law or whether the case will descend - as many corruption cases do - to actors in the process not following procedures appropriately and consequently facing nothing more than disciplinary action or perhaps not even this. It does, however, represent a very interesting insight to how corruption may emerge in large-scale contracting.

\section{Conclusion}

Improvements in the domain of morality are evident in several areas of life, many of which are related to the context of (anti-)corruption. Examples are governance, with the growth of liberal democracies and decline of theocracies and autocracies; economics, with the increased freedom of movement of people, goods and services; human rights, with increased access to the voting system, freedom of speech and the right to protest; to name a few (Shermer 2015). Now, the cultural context in which these improvements take place or does not take place is naturally relevant. As recent research has shown, real or perceived norms can impact corrupt behavior (negatively), providing some explanations for inter-personal and inter-cultural variations in corrupt behavior (Köbis, van Prooijen, Righetti, and Van Lange 2015). Yet, the cultural context is only partly relevant in explaining behavior, not in establishing a moral peak. 
This research uses official documents on (anti-)corruption as a moral compass to identify the peak; however, it is important to reiterate that there quite possibly exists multiple peaks. Nonetheless, this is one of them. The EU moral peak was established by synthesizing official documents. The synthesis established a theoretical framework as a representation of the EU stance on corruption, i.e. the moral peak defined as:

"Corruption is detrimental and should not be performed nor condoned by anyone, anywhere at any time."

This conclusion is obviously not very surprising, but as made quite clear by the case description, there are issues with the actions of the actors which do not conform to this moral stance.

The case, still on-going, may, in the end, present some signs of moral peak actions. But, when looking at its transpired parts, it does not display peak performance. Thus, when matching the moral peak to the actions within any of these parts, the final conclusion is the same - the decisions and resulting actions are morally corrupt. This conclusion obviously supersedes the legal interpretation of cultural norms as, for this discussion, the concern is not with corruption as an illegal activity as defined by the law in any given country. Rather the focus is on how the decisions and expressed intentions triangulate a position on the moral landscape. It is, however, not viable to simply assert which moral beliefs are superior on an arbitrary basis; reasons must be provided and those reasons have to be grounded in rational arguments and empirical evidence. It is the comparison of the moral peak definition with the qualitative analysis of the empirical data from the case that clearly illustrates a significant gap between rhetoric and reality - the expressed EU position on corruption and the actual practice.

\section{Discussion}


After decades of a global, more or less coordinated, fight against corruption, the question remains: How can we create a non-corrupt flourishing human society based upon universal morals where distribution of goods is not a function of undue advantages? Having shed some light on where the potential application of a moral peak values and norms falls victim to the dark embrace of corruption some things do become clearer. If global anti-corruption initiatives are to be successful in, and particularly across, more than one social setting it should take variations in values and norms under close consideration.

Overall, the history of anti-corruption efforts does not consequently inspire hope for success, where often the lackluster application of some universal cure has proved ineffective. The few anticorruption success stories involved policy implementation that took new paths, even going against international standardized advice ${ }^{3}$ and counter-intuitively reducing complex anti-corruption legislation as a high amount of legislation is associated with not less, but more corruption ${ }^{4}$. Repressive measures alone are not sufficient to tackle corruption in an effective manner (COM(2014) 38 2014). Nevertheless, the ability of a judicial system to effectively impose proportionate and dissuasive criminal sanctions plays a major deterrent role; moreover, it is a clear sign that corruption is not tolerated. That, in turn is perfectly in line with the moral peak stance on corruption - zero tolerance. Thus, morality obviously has a role in any successful anti-corruption effort, but it is important to understand the limits of norms and values.

As echoed in the ANTICORP project - We need to rethink the way we do anti-corruption. Instruments that were promoted for years do not work the way we expected them to. They only work under certain societal conditions. We therefore must move away from thinking of anticorruption as a blueprint that can be applied anywhere (Mungiu-Pippidi \& Dadasov, forthcoming).

\footnotetext{
${ }^{3}$ For more on how some European countries managed to have a transition where corruption was prevented, and to design a government which minimised opportunities for corruption, see Mungiu-Pippidi (2015) ${ }^{4}$ For a deeper analysis of how consolidated democracies - employ less regulation, yet better control of corruption see Mungiu-Pippidi et al. (2015).
} 
Corruption is a complex phenomenon with economic, social, political and cultural dimensions, which cannot be easily eliminated. An effective policy response cannot be reduced to a standard set of measures; there is no 'one size fits all' solution. (COM(2014) 38 2014)

Now, the argument is not that there are no universal morals to be found; in fact, it is the exact opposite. There are most certainly universal morals that can be defined for a moral peak. The tools to reach that peak, however, are not the same all over the world. The point is that there are universal laws about morality to be found and that can established as facts conducive to the prosperity and good governance of human society. Those laws, however, must be dealt with differently in the highly varied cultural context of the world - as long as one remembers, acknowledges and takes into consideration those universal laws.

The policy maker painstakingly bends down to pick up the pen. When doing so while carefully balancing the documents, he realizes, even though there may be anti-corruption policy based on morals as universal as gravity, the concept is dealt with very differently. Just as the laws governing gravity are clear and indisputable, and certainly not versions of the truth, recalling a documentary saying: "Gravity is not a version of the truth. It is the truth. Anyone who doubts it is invited to jump out a tenth-story window." (Dawkins 2008). The same is true for the concept of universal moral laws about morality. Nonetheless, the concept is dealt with very differently, universal laws notwithstanding, it is not the same way if you are policy maker trying hard not to drop an overwhelming bundle of documents, a long-range sniper fighting IS terrorists or a fighter pilot protecting European airspace.

The universal moral laws must be established, understood and considered - and then dealt with according to a specific context. In the case study, all the types described by Rusch (2016) seem to exist, jostle and collide. Specifically, when considering the fourth and fifth type: 'commitment and 
consistency'; and 'social proof'. It is quite possible that the actors prompting Mr. Alan towards corruption, particularly since he does not immediately embrace the idea of partaking in the corrupt behavior, feel partly motivated by an internal pressure to act consistently with the commitment for corrupt behavior. Thus, faced with an ambiguous situation, Mr. Alan initially allows things to proceed, effectively taking cues from others in the vicinity on how to act. While at the same time, trying to find a rational, non-corrupt, explanation for what most would consider blatant corruption. Finally, in lieu of any plausible explanation that does not involve immoral and corrupt behavior, Mr. Alan blows the whistle.

The case may or may not involve corruption to a degree that is provable and subsequently judged upon, but there is most certainly something going on. Something that, if nothing else, is morally questionable involving undeclared interests and past associations. This highlights the importance for prevention of corruption. Prevention that is not just limited to a time and place before anything has happened but a perpetually available option as soon as someone discovers that something may be happening. Going back to the food analogy. It is quite clearly more resource demanding to cure someone that has already been poisoned by consuming "bad" food - leading to obesity and diabetes etc. - than it is to prevent someone from doing it in the first place. Also, it would not be fair for the friend that points out the ongoing consumption of poison to be scolded and shunned for doing so. Analogies aside, in the real world an effective anti-corruption policy should balance prevention and repression. While room is often given for the latter, the former needs further emphasis. When it comes to corruption, prevention truly is better than a cure, which in turn, amongst other things, calls for further instrumentalization of early detection systems and whistleblower protection. 


\section{References}

Bahm, Archie J. Axiology: The Science of Values. Amsterdam: Rodopi, 1993.

Bazerman, Max, and Ann Tenbrunsel. (2017). "Stumbling Into Bad Behavior." The New York Times, April 20, 2011. Accessed April 17, 2017. http://www.nytimes.com/2011/04/21/opinion/21bazerman.html.

Cialdini, Robert. Influence: The Psychology of Persuasion. New York: Quill, 1993.

Council of Europe. Criminal Law Convention on Corruption (CoE ETS No.173), 2002.

Council of Europe. Civil Law Convention on Corruption (CoE ETS No.174), 2003.

Darley, John M. "The Cognitive and Social Psychology of the Contagious Organizational Corruption." Brooklyn Law Review 70 (4) (2005): 1177-1194.

Dawkins, Richard. The Genius of Charles Darwin - HD Full Length (All 3 Episodes). Accessed April 30, 2017. https://www.youtube.com/watch?v=A0VnuhHq5m0.

van Duyne, Petrus C. "Will Caligula Go Transparent? Corruption in Acts \& Attitudes." Forum on Crime and Society 1(2) (2001): 7398.

European Commission. Report from the Commission to the Council based on Article 9 of the Council Framework Decision 2003/568/JHA of 22 July 2003 on Combating Corruption in the Private Sector (COM(2007) 328), 2007.

European Commission. Report from the Commission to the European Parliament and the Council, based on Article 9 of Council Framework Decision 2003/568/JHA of 22 July 2003 on combating corruption in the private sector (COM(2011) 309), 2011.

European Commission. EU Anti-Corruption Report (COM(2014) 38), 2014. 
Fazekas, Mihaly, Luciana Cingolani, and Bence Tóth. A comprehensive review of objective corruption proxies in public procurement: risky actors, transactions, and vehicles of rent extraction. Working Paper series: GTI-WP/2016:03. Budapest: Government Transparency Institute, 2016.

Feldman, Richard. Epistemology. Upper Saddle River: Pearson Education, 2003.

Hammersley, Martyn. "What's Wrong with Ethnography? The Myth of Theoretical Description." Sociology 24 (4) (1990): 597-615.

Harris, Sam. Science can answer moral questions. Accessed April 1, 2017. https://www.ted.com/talks/sam_harris_science_can_show_what_s_right.

Harris, Sam. The Moral Landscape: How Science Can Determine Human Values. New York et al.: Free Press, 2011

Heidenheimer, Arnold J. "Perspectives on the Perception of Corruption." In Political CorruptionConcepts and Contexts, edited by Arnold J. Heidenheimer and Michael Johnston, 141-154. New Brunswick; London: Transaction Publishers, 2002.

Kahneman, Daniel. Thinking, Fast and Slow. New York: Farrar, Straus and Giroux, 2011.

Köbis, Nils C., Jan-Willem van Prooijen, Francesca Righetti, and Paul A. M. van Lange. "Who Doesn't?-The Impact of Descriptive Norms on Corruption." PLoS ONE 10(6) (2015): e0131830.

OECD. Integrity in Public Procurement. Good Practice from A to Z. Paris: OECD, 2007.

OECD. OECD Principles for Integrity in Public Procurement. Paris: OECD, 2009.

OECD. Government at a Glance 2013. Paris: OECD, 2013. 
Pallier, Gerry, Rebecca Wilkinson, Vanessa Danthiir, Sabina Kleitman, Goran Knezevic, Lazar Stankov, and Richard Roberts. "The Role of Individual Differences in the Accuracy of Confidence Judgments." Journal of General Psychology 129 (3) (2002): 257-299.

Persson, Anna, Bo Rothstein, and Jan Teorell. "Why Anticorruption Reforms Fail. Systemic Corruption as a Collective Action Problem." Governance 26 (3) (2013): 449-471.

Mungiu-Pippidi, Alina, and Ramin Dadasov. "When Do Laws Matter? The Evidence on National Integrity Enabling Contexts" Crime, Law and Social Change, forthcoming.

Mungiu-Pippidi, Alina. The Quest for Good Governance: How Societies Develop Control of Corruption. Cambridge: Cambridge University Press, 2015.

Mungiu-Pippidi, Alina et al. Public Integrity and Trust in the European Union. Berlin: ERCAS, Hertie School of Governance, 2015.

Nohria, Nitin. "You're not as virtuous as you think." The Washington Post, October 15, 2015. Accessed April 17, 2017. https://www.washingtonpost.com/opinions/youre-not-as-virtuousas-you-think/2015/10/15/fec227c4-66b4-11e5-9ef3fde182507eac_story.html?utm_term=.f6095dc2b4db.

Robson, Colin. Real World Research. Chichester: John Wiley \& Sons, 2011.

Rusch, Jonathan. The Social Psychology of Corruption. Paper presented at the 2016 OECD Integrity Forum, Paris, 2016.

Sampford, Charles, Arthur Shacklock, Carmel Connors, and Fredrik Galtung. Measuring Corruption. Aldershot: Ashgate Publishing Limited, 2006.

Shermer, Michael. The Moral Arc: How Science Makes Us Better People. New York: Henry Holt and Company, 2015. 
The Council of the European Union. Council Framework Decision 2003/568/JHA of 22 July 2003 on Combating Corruption in the Private Sector (COM(2003) 568), 2003.

The Council of the European Union. Council Decision of 25 September 2008 on the conclusion, on behalf of the European Community, of the United Nations Convention against Corruption $(\operatorname{COM}(2008) 801), 2008$.

The Council of the European Union. The Stockholm Programme - An Open and Secure Europe Serving and Protecting Citizens (OJ C 115/1), 2009.

United Nations General Assembly, Res.A/58/422. The United Nations Convention Against Corruption, 2003.

Wensink, Wim, and Jan Maarten de Vet. Identifying and Reducing Corruption in Public Procurement in the EU. Brussels: PwC / ECORYS, 2013.

Williamson, Kirsty. "Research in Constructivist Frameworks Using Ethnographic Techniques." Library Trends 55 (1) (2006): 83-101. 